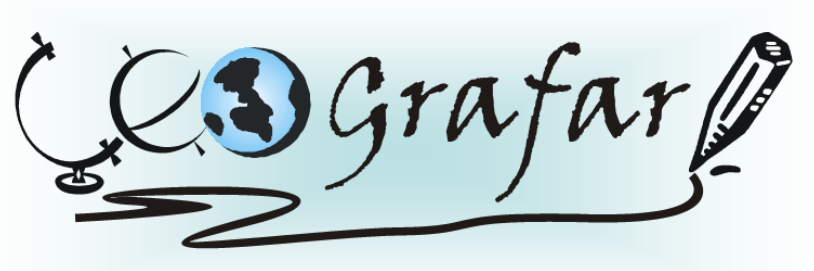

Revista Eletrônica do Programa de Pós-Graduação em Geografia - UFPR

\title{
A CENTRALIDADE DE LONDRINA - PR NA REDE URBANA BRASILEIRA: DE CENTRO REGIONAL AO NÍVEL SUBMETROPOLITANO
}

\section{THE CENTRALITY OF LONDRINA - PR IN BRAZIL'S URBAN NETWORK: FROM THE REGIONAL CENTER TO THE SUBMETROPOLITAN LEVEL}

(Recebido em 28.08.2014; Aceito em: 09.02.2015)

Tânia Maria Fresca

Prof $^{a}$. Dr ${ }^{a}$. do Departamento de Geociências

Universidade Estadual de Londrina

Londrina, PR, Brasil

E-mail: tania_geografia@yahoo.com.br

\begin{abstract}
RESUMO
O objetivo do artigo é realizar uma discussão sobre as transformações no nível de centralidade da cidade de Londrina - PR na rede urbana brasileira, a partir de pesquisas realizadas para a escala nacional. Trata-se de estudos realizados por Geiger (1963), IBGE (1972, 1987, 2000, 2008) e IPEA (2000). Com base nestes, bibliografias específicas para Londrina e levantamentos de dados, procura-se entender e discutir criticamente sua centralidade em diferentes momentos. Os trabalhos permitiram evidenciar que a mesma apresentava-se como um centro regional nos anos de 1950, alcançando a centralidade submetropolitana no final dos anos de 1970 e assim permaneceu até o inicio dos anos de 1990. Esta posição foi ratificada no início dos anos 2000 pelo IPEA, incluindo-se ainda o fato de considerála como uma aglomeração urbana de maior porte. No último trabalho do IBGE sobre a rede urbana nacional a considerou como uma capital regional de nível B. Esta posição é criticamente analisada a partir de elementos como a forma urbana e os deslocamentos pendulares na aglomeração urbana, as atividades comerciais e prestadoras de serviços, que demonstram tratar-se de um escalão urbano bastante complexo, que a aproxima cada vez mais de escalão metropolitano.
\end{abstract}

Palavras-chave: Rede Urbana Brasileira. Londrina - PR. Centralidade. 


\begin{abstract}
The aim of this article is to discuss the changes in the level of centrality of LondrinaPR in Brazil's urban network, based on researches for the national scale. These are studies by Geiger (1963), IBGE (1972, 1987, 2000, 2008) e IPEA (2000). Based on these, specific bibliographies for Londrina and data surveys, it seeks to understand and critically discuss its centrality in different moments. That works have highlighted that it presented itself as a regional center in the 1950s, reaching the submetropolitan centrality in the late 1970 s and remained so until the early 1990s. This position was confirmed in the early 2000 by IPEA, still including the fact considers it as an urban agglomeration of larger size. The latter work the IBGE on the national urban network, even considered as a regional capital level $B$. This position is critically analyzed from several elements such as: urban shape and commuting in urban agglomeration, service providers and commercial activities, demonstrating that it is a very complex urban level, that draws ever closer to the metropolitan level.
\end{abstract}

Keywords: Brazilian Urban Network; Londrina - PR; Centralility.

\title{
INTRODUÇÃO
}

Os estudos sobre a rede urbana brasileira configuram-se em importantes contribuições ao entendimento de transformações que vem ocorrendo no processo de urbanização brasileiro desde os anos de 1950. Isto porque: a) são pesquisas que apresentam um conjunto de informações sobre a distribuição de bens e serviços que os núcleos urbanos realizam; b) permitem identificar os níveis de centralidades dos centros urbanos com suas respectivas áreas de influências; c) efetuar estudos sobre as transformações e dinâmica da rede urbana e a inserção de cidades em diferentes momentos; d) permitem entender e discutir seus aportes teóricos e diferentes metodologias aplicadas.

Destacam-se aqui, os estudos realizados por Geiger (1963), pelo IBGE (1972, 1987, 2000, 2008) e IPEA (2000) para a rede urbana nacional. Se há críticas a estes trabalhos, as mesmas não contestam sua validade no sentido de que, os estudos identificaram inúmeras mudanças na rede urbana e na centralidade dos centros vinculados à oferta de bens e serviços. Assim, o presente trabalho tem por objetivo discutir as transformações no nível de centralidade de Londrina, localizada no Norte do Paraná a partir dos estudos realizados para a escala nacional, centrando atenção na emergência do nível submetropolitano, cujos processos de transformações ainda estão em curso. 
Em realidade, trata-se de discutir a continuidade do processo de metropolização no Brasil, que se realiza por diferentes caminhos. Neste sentido é necessário explicitar que a metropolização configura-se em um processo que cria metrópoles. Mas enquanto cidades não se tornam metrópoles, se este for possível diante de inúmeros fatores, o processo vai espraiando, onde condições de inúmeras ordens o permitam, características que são consideradas metropolitanas.

Metodologicamente o estudo apoiou-se na análise dos trabalhos de Geiger (1963), o primeiro em escala nacional, que evidenciou aspectos do desenvolvimento nacional e da evolução da rede urbana; do IBGE (1972, 1987, 2000, 2008) e IPEA (2000), enquanto estudos para a rede nacional, explicitando aspectos de seus pressupostos teóricos e metodológicos. A estas foram acrescidas bibliografias sobre Londrina e levantamentos de dados, de modo a discutir os diferentes níveis de sua centralidade, bem como evidenciar como esta cidade já colocava-se com nível submetropolitano desde o final dos anos de 1970. Defende-se aqui a continuidade desta centralidade, embora divergindo criticamente e com base em estudos, das análises efetuadas pelo IBGE (2008).

O trabalho está dividido em três partes, exclusa a introdução. Na primeira discute-se Londrina como um centro regional nos anos de 1950 e 1960, explicitando como uma cidade de pouco mais de duas décadas, no contexto da frente pioneira paranaense, ascendeu a esta centralidade. Na segunda parte, apresenta-se a emergência do nível submetropolitano nos anos de 1970 e sua manutenção até o começo do século XXI para a cidade em estudo. Na terceira parte tem-se o último estudo do IBGE (2008), apresentando seus princípios teóricos e metodológicos, como percurso para questionar a centralidade atribuída à Londrina. A título de considerações finais, expõe-se elementos que ratificam a posição desta cidade como um centro submetropolitano.

\section{LONDRINA COMO CENTRO REGIONAL}

Londrina configura-se no presente momento como uma cidade bastante importante do ponto de vista do conjunto de suas atividades econômicas, seja no âmbito do estado do Paraná, como na Região Sul do país. Esta importância advém de longo tempo, cujos estudos geográficos já apontavam tal fato desde os anos de 
1950. A começar pelo trabalho de Geiger (1963), em cuja análise da rede urbana brasileira, considerava Londrina como uma capital regional vinculada à rede urbana da metrópole paulista.

Tendo em conta que a cidade teve sua gênese em 1929 e que os dados utilizados para a análise foram dos anos de 1950, denota-se que mesmo sendo jovem, sua dinâmica econômica e social apoiada na pequena produção mercantil agrícola e urbana, permitiu que a mesma desenvolvesse atividades econômicas comércio atacadista, varejista, prestação de serviços e algumas atividades industriais, particularmente a alimentícia e moveleira - que a colocavam como a mais importante do Norte do Paraná naquele momento. $O$ autor ressaltava a partir da legenda de uma foto de 1955 da cidade, que a mesma apresentava:

[...] modernas formas de vida, com elevação de prédios de muitos andares e, relativamente animada circulação de automóvel, em Londrina, médio centro comercial de região agrícola próspera. Na rede urbana de São Paulo, Londrina tem a hierarquia de principal centro do norte do Paraná, região cafeeira nova (GEIGER, 1963, p. 56).

Estar vinculada a rede urbana da metrópole paulista, ratificava as ligações econômicas e sociais que Londrina estabeleceu desde sua gênese, com São Paulo, o centro dinâmico da economia nacional. Ao mesmo tempo, Geiger (1963, p. 252) considerava Curitiba como sendo uma capital regional "maior", tendo como fatores de seu desenvolvimento, o fato de ser capital do estado do Paraná e ser dinamizada pelos negócios da cafeicultura, além de estar naquele momento, vinculada a rede urbana paulista.

Neste sentido, é necessário explicitar como a cafeicultura era uma atividade de fundamental importância, praticada em quase todo o norte do estado. Esta envolvia ainda importante produção de gêneros alimentícios e matérias primas destinada ao mercado interno, enquanto o café era destinado ao mercado externo, inserindo o norte do Paraná em uma divisão do trabalho bastante complexa; produções estas praticadas por pequenos proprietários rurais com mão de obra familiar, cujo cerne da mesma era o mercado; gerava importantes divisas ao governo estadual.

Estes elementos são melhores compreendidos quando se entende a formação social (SANTOS, 1982) do norte do Paraná, a partir dos anos de 1930. 
Tratava-se de uma formação social baseada predominantemente na pequena propriedade rural, utilizando-se mão de obra familiar, cuja produção agrícola era destinada ao mercado nacional com gêneros alimentícios e matérias primas, enquanto o café destinava-se ao mercado internacional. Para essa base produtiva rural, era necessária a presença de inúmeros núcleos urbanos criados no contexto dos grandes loteamentos, que atendessem as demandas do campo em termos de transporte, sistema de comercialização da produção, bem como outros bens e serviços também para a população urbana. Emerge nesta formação social de pequenas propriedades, uma vigorosa produção mercantil, inclusa a urbana, cujas rendas e lucros eram reinvestidos fortemente no próprio lugar, permitindo uma dinâmica econômica e social bastante acentuada (FRESCA, 2007).

Londrina neste contexto, colocava-se como o centro dinâmico desta produção, mantendo-se no controle da maior parcela de sua comercialização pela presença de importantes escritórios de exportação, máquinas de beneficiamento do produto, sistema bancário que incluía ainda banco local, recebendo inclusive a adjetivação nos anos de 1950, de "capital mundial do café". Ao mesmo tempo, parcela da renda auferida com esta atividade foi reinvestida na cidade em diversas atividades urbanas. Exemplar deste processo foi o investimento em edifícios verticais: durante a década de 1950 foram produzidos 17 edifícios com pavimentos que oscilavam de 07 a 22. Destaque dentre os mesmos foi o Centro Comercial, um conjunto de 3 edifícios com 22 pavimentos cada, cujo térreo era para atividades comerciais e os demais para residência com diferentes áreas internas (CASARIL, 2011; MELO, 2014). Não deixa de ser importante a referência a Prandini (1952) relatando que "[...] os edifícios de vários andares já começaram a surgir, não como índice de falta de espaço, mas atestando a riqueza da cidade e a sua chegada a uma base de princípios de maturidade" (PRANDINI, 1952, p. 68).

Na mesma perspectiva, isto é, da importante dinâmica econômica na cidade, Linardi (1995) chamava a atenção para o fato de Londrina apresentar o mais importante comércio varejista diversificado e com elementos de sofisticação, contanto com agências de vendas de automóveis, agências de bancos com atuação regional e nacional, filiais de redes nacionais de tecidos e confecções, lojas especializadas na comercialização de produtos de luxo, dentre outros. Assim, quando Geiger (1963) colocava que Londrina apresentava a mais importante 
hierarquia urbana do Norte do Paraná, os elementos acima indicavam os caminhos através dos quais tal centralidade se realizou nos anos de 1950.

Outra referência importante foi a Divisão do Brasil em Regiões Funcionais Urbanas, realizada na segunda metade dos anos de 1960 e publicada em 1972 (IBGE, 1972). Na realidade, tratava-se da "[...] reelaboração técnica e revisão atualizada do estudo [...] Esboço Preliminar da Divisão do Brasil em Regiões Polarizadas" de 1967 (IBGE, 1972, p. 4).

Este trabalho analisou a rede urbana brasileira de acordo com as regiões funcionais complexas utilizando-se de muitos critérios e variáveis. Com base nos modelos de Hagget e Cholley foi estabelecida "[...] uma estrutura simplificada da realidade que apresenta, supostamente, características ou relações de forma generalizada" (IBGE, 1972, p. 10). Em outros termos, buscava-se em uma estrutura - sistema - simplificada de divisões territoriais por agrupamentos e dos núcleos urbanos hierarquizados.

Esta hierarquia foi estabelecida a partir da contagem de relacionamentos entre as cidades, utilizando-se fluxos agrícolas, distribuição de serviços à economia e população. A estes foi utilizado ainda o conceito de setores básico e não - básico para levantar e analisar os fluxos e relacionamentos em uma região funcional urbana, utilizando dois indicadores: a rede viária com o movimento de passageiros e a pesquisa direta (IBGE, 1972, p. 10). Desta maneira, verificou-se a partir da distribuição de bens e serviços pelas localidades centrais, sua posição hierárquica na rede urbana.

A pesquisa identificou quatro níveis hierárquicos: centros metropolitanos subdivididos em 1 A (grande metrópole nacional), 1B (grande metrópole), 1C (centros metropolitanos), 1D (centros macrorregionais), demonstrando grandes diferenças dentre aquelas consideradas metropolitanas; centros regionais subdivididos em A e B; centros sub-regionais e centros locais, também subdivididos em A e B.

Esta pesquisa tem relação direta com outros estudos que estavam sendo realizados pelo IBGE em direção ao estabelecimento das primeiras regiões metropolitanas no Brasil, em um contexto de forte presença do Estado nacional na busca de implantação de planejamento urbano e regional. Tanto assim que, em 1969 foram publicados alguns dos primeiros trabalhos para determinação de áreas 
metropolitanas no país (GALVÃO et. al, 1969) e o estabelecimento da divisão regional brasileira de 1969 em grandes regiões e microrregiões homogêneas (GALVÃO; FAISSOL, 1969). Galvão et. al. (1969) evidenciava que o estudo das regiões funcionais identificou nove cidades como metrópoles nacionais e regionais. No entanto, indicava "[...] maior diversificação funcional nelas existentes, e esta diversificação funcional está sempre associada a um contingente populacional nunca inferior a 400.000 habitantes" (GALVÃO et. al., 1969, p. 61).

No contexto de rápido avanço da urbanização brasileira; de intensas transformações em sua estrutura produtiva em direção aos investimentos estatais na industrialização nos segmentos como química, química fina, aeronáutica, dentre outros; no avanço das alterações na agropecuária pelo caminho da modernização, com a incorporação de mais ciência e técnica, de outros cultivos e criações de animais; alterações nas relações de trabalho em direção ao avanço do assalariamento, etc.; a metropolização avançava no Brasil com necessários investimentos urbanos para garantir condições gerais necessárias à produção e reprodução do capital.

Assim, o primeiro estudo sobre a rede urbana brasileira, realizado pelo IBGE (1972) já demonstrava a complexidade da urbanização nacional, bem como a enorme diversidade de centros urbanos no que se refere a sua centralidade, vinculada à oferta de bens e serviços.

No caso da rede urbana de São Paulo, as cidades consideradas centros regionais de nível A foram Bauru, Campinas, Ribeirão Preto e São José do Rio Preto localizadas no estado de São Paulo, Londrina no Paraná, Campo Grande no Mato Grosso do Sul e Uberlândia no estado de Minas Gerais. No caso da rede urbana de Curitiba, esta cidade foi considerada pelo IBGE (1972, p. 15), como um centro macrorregional 1D, e portanto, inserida no nível metropolitano. Suas capitais regionais de nível A eram Ponta Grossa-PR, Blumenau e Florianópolis - SC.

Estes elementos são importantes porque demonstraram as mudanças que ocorreram na rede urbana: Curitiba não exercia influência direta no norte do estado do Paraná referente à distribuição de bens e serviços naquele momento; estendendo seu raio de atuação para o estado de Santa Catarina. Desta maneira Londrina continuou a integrar a rede paulista de então, na condição de centro regional $A$, significando que suas ligações se faziam diretamente com São Paulo, sem 
intermediação de outros centros urbanos de maior hierarquia, com destaque na distribuição de bens e serviços, comércio atacadista, com importante atuação extra regional e "[...] no comando de uma área com estruturação urbana definida, contendo centros dos escalões inferiores" (IBGE, 1972, p. 15).

Sua área de influência ia de Cornélio Procópio até Apucarana; a porção extremo leste do norte do estado estava na área de influência de Ponta Grossa; a partir de Apucarana, sentido oeste, estava na área de influência de Maringá. Esta pesquisa já estabelecia algumas diferenças em relação ao trabalho de Geiger (1963), pois identificava no norte do Paraná além de Londrina, a cidade de Maringá como um centro regional, mas ocupando posição de menor destaque que a primeira, e ambas vinculadas à metrópole paulista.

\section{A EMERGÊNCIA DO NÍVEL SUBMETROPOLITANO PARA LONDRINA NOS ANOS DE 1970}

A importância de Londrina do ponto de vista de seu papel enquanto distribuidora de bens e serviços para uma grande área de influência, também foi ratificada no estudo das Regiões de Influência das Cidades, cujos dados são de 1978, a conclusão em 1983 e publicação em 1987 (IBGE, 1987). Apoiado na Teoria das Localidades Centrais e extensões à formulação clássica (CORRÊA, 1982), levou em conta a existência dos dois circuitos da economia urbana para a distribuição de bens; o caráter histórico da análise ligada às mudanças oriundas da dinâmica econômica e social do país; à presença de feiras com diferentes periodicidades como outra forma de oferta de bens; a dinâmica da diferenciação regional, ressaltada por diferentes participações dos núcleos urbanos na divisão territorial do trabalho. Mas, destacava ainda que as cidades desempenhavam outras atividades além da distribuição de bens e serviços, que se correlacionavam com a posição da mesma na rede urbana.

Outro aspecto crucial ao entendimento do papel das cidades nesta pesquisa vinculava-se à circulação dos excedentes sociais na forma de renda fundiária e lucros, que implicavam em investimentos, consumo, comercialização, migração, presença de sede de empresas, dentre outras. Evidente que o entendimento da circulação do excedente articulava-se à produção, distribuição e consumo. A partir 
de tais pressupostos, a teoria das localidades centrais passou a ser uma referência importante, mas seus pressupostos não foram utilizados conforme colocados por Christaller.

Assim, a pesquisa do IBGE (1987, p. 19-21) identificou 6 níveis hierárquicos: metrópole que subdividia-se em nacional e regional; centro submetropolitano; capital regional; centro sub-regional; centro de zona e centro local. Importa aqui a centralidade submetropolitana, pois tratava-se da emergência de um novo escalão hierárquico identificado na pesquisa, já que Londrina era uma destas cidades.

\begin{abstract}
Os centros sub-metropolitanos [sic] se definem por sua situação intermediária entre os níveis de capital regional e metrópole, e se caracterizam por uma atuação extremamente importante através de funções definidoras do nível metropolitano em setor de um território onde uma metrópole regional atua, subordinando o próprio centro submetropolitano [sic]. Em outros termos a atuação desse tipo de centro não se limita às funções de capital regional, mas espacialmente, sua atuação não apresenta a magnitude de uma região de influência de uma metrópole regional. [...] a emergência desse tipo de centro decorre, de um lado, da centralização da vida econômica de várias Unidades da Federação em suas capitais estaduais, cabendo certamente papel relevante ao Estado como promotor da ascensão hierárquica da capital: São Luís, Teresina, Natal, o conjunto João Pessoa - Campina Grande, Maceió, Aracaju, Vitória, Cuiabá e Campo Grande constituem nos casos em questão. Na região Centro-Sul, por outro lado, emergem centros sub-metropolitanos [sic] e outros devem emergir - em função de fatores outros que não a ação centralizadora exercida pelo Estado: Juiz de Fora, Campinas, Ribeirão Preto e Londrina são exemplos (IBGE, 1987, p. 22).
\end{abstract}

A própria pesquisa não esperava emergir tal escalão urbano, tendo sido encontrado a posteriori, evidenciando a continuidade de processos que alteram a rede urbana e a inserção dos centros urbanos, tornando-a mais desigualmente complexa. Em realidade, no final dos anos de 1970 os intensos processos de transformações da sociedade brasileira que vieram sendo realizados desde os anos de 1950, alteraram em muito a dinâmica econômica, social, populacional e territorial de Londrina.

Destacam-se aqui as transformações agrárias marcadas pela substituição de culturas em favor daquelas de elevado nível tecnológico como o binômio da sojatrigo. A inserção destas no contexto estadual, nacional e internacional, permitiu, por caminhos diversos, a criação do Instituto Agronômico do Paraná - IAPAR - em 1972 com sede em Londrina e a implantação do Centro Nacional de Pesquisas da Soja da 
Embrapa em 1975 na cidade em tela (CAMPOS, 2010); alterações nas relações sociais em direção à ampliação do assalariamento; forte êxodo rural; alterações na dinâmica populacional com aumento da taxa de urbanização, mas com continuidade do crescimento da população total; ampliação e diversificação das atividades comerciais e prestadoras de serviços, atendendo demandas reais ou criadas pela expansão do consumo de massa e melhoria do sistema de transporte e comunicação.

Situação que marca o dinamismo econômico da cidade de Londrina nos anos de 1960 e que se manifestou nos estudos do IBGE dos anos de 1970, foi a criação do Serviço de Comunicações Telefônicas - Sercomtel - em 1964, mas com funcionamento a partir de 1968 como uma autarquia municipal. Isso permitiu que a cidade se tornasse uma das poucas no contexto nacional daquele momento, a contar com os serviços telefônicos com o serviço de discagem direta à distância DDD - a partir de 1971, juntamente com São Paulo, Curitiba e Porto Alegre. Tal criação decorreu em parte, pelo fato da Telecomunicações do Paraná - Telepar ainda não ter expandido este serviço para o norte do estado.

Outro elemento do dinamismo londrinense refere-se à implantação em 1973, do primeiro shopping-center da cidade, o Com Tour, com mais de $13 \mathrm{mil} \mathrm{m}^{2}$. Fruto de investimentos locais entre imobiliárias, construtoras e empresários diversos, foi o terceiro shopping center inaugurado no país, reunindo um conjunto de lojas como Kopenhagen, Hobjeto Móveis, Cristais e Malhas Hering, tecelagem Capp, além do supermercado Pag Pouco, posto de gasolina e um cine teatro. Criado como shopping center para atuação regional, figurou como o único até 1990, quando outro foi inaugurado na cidade. Acrescente-se ainda a criação da Universidade Estadual de Londrina em 1971, congregando diversas faculdades criadas ao longo dos anos de 1950/60, dentre outras (FRESCA, 2013 a).

Em realidade os elementos apontados indicam tratar-se de um momento de divergência para Londrina, isto é, um conjunto de fatores e processos que inseriram a cidade em outra etapa da divisão territorial do trabalho. Os conceitos de convergência e divergência apresentam poder explicativo para as complexas mudanças que envolvem as transformações da organização espacial. Convergência e divergência são, na interpretação de Bessa (2007), processos que coexistem, 
constituindo-se ademais, em trajetórias que conduzem a resultados distintos, já que decorrentes da dinâmica econômica, política e sociocultural.

Estes processos existem em quatro combinações possíveis, considerando-se uma dada formação socioespacial, intervalo de tempo e duração indeterminada: convergência-divergência; divergência-convergência; convergência-convergência e divergência-divergência. A convergência originando-se de situações distintas gera resultados similares, enquanto a divergência originando-se de uma mesma situação gera resultados diferentes. Tais combinações deixam em evidência situações de homogeneidade e diferenciação, demonstrando o movimento e o ritmo das mudanças.

Desta maneira, processos de convergência e divergência para Londrina a partir da produção propriamente dita, evidenciam de modo geral que, até os anos de 1960 processos de diversas ordens conduziram o desenvolvimento econômico, social e espacial em direção a uma condição de convergência liderada pela produção cafeeira, de gêneros alimentícios e matérias primas para o mercado, com base em pequenas propriedades e mão de obra predominantemente familiar. A partir de então ocorreram significativas mudanças em sua evolução, em direção à outra inserção na divisão do trabalho, oriunda de fatores internos e externos como foi a introdução da soja e trigo. Nesse momento de transformações, verificou-se o início da implantação de um conjunto de atividades de pesquisa e desenvolvimento ligado à agricultura, o de atividades terciárias mais complexas, enquanto a produção industrial passou a ter maior destaque a partir dos anos de 1990, no contexto da denominada reestruturação produtiva.

Assim, quando o IBGE (1987) identificou e considerou Londrina como um centro submetropolitano, isto significou que a mesma apresentava um conjunto de atividades urbanas bastante complexas, cuja área de atuação se assentava em todo norte do Paraná, já que Maringá colocava-se como capital regional na área de influência de Londrina. No entanto, a cidade estava agora inserida na rede urbana de Curitiba, embora diversos estudos demonstrem que as relações econômicas e sociais mais importantes fossem estabelecidas com São Paulo, enquanto com Curitiba as relações eram muito mais políticas e administrativas.

Situação similar foi identificada para Londrina no estudo das Regiões de Influência das Cidades de 1993 (IBGE, 2000). Apoiado em princípios teóricos de 
Christaller, acrescido dos avanços à mesma conforme Corrêa (1982), procurou mediante uma visão crítica relações entre a organização espacial da distribuição de bens e serviços e sua projeção espacial, enquanto parte da totalidade social (IBGE, 2000, p. 20). Baseou-se ainda nas discussões sobre redes de circulação, poder e decisão.

Diferenciava-se do trabalho anterior pela identificação de 08 níveis de centralidade. O nível máximo correspondia ao metropolitano, mantendo-se ainda as nove metrópoles definidas desde os anos de 1970; a centralidade muito forte correspondia predominantemente ao submetropolitano, totalizando 24 cidades no país como Campinas, Manaus, Ribeirão Preto, Uberlândia, Juiz de Fora, Belém, São Luís, Teresina, Passo Fundo, Florianópolis, dentre outras; a centralidade forte correspondia as capitais regionais; o nível forte para médio vinculava-se aos centros sub-regionais; de médio para fraco correspondia predominantemente aos centros de zona; o fraco foi considerado como tendendo a centro de zona, enquanto o muito fraco eram predominantemente os centros locais (IBGE, 2000, p. 25).

Observa-se que neste estudo é mais amplo o número de centralidades, que sobre certos aspectos, procurava dar conta da enorme diversidade de escalões urbanos na rede nacional. Quanto mais complexa é a divisão do trabalho, maiores as tendências à diversificação qualitativa dos centros urbanos.

No caso do Paraná, o nível metropolitano estava em Curitiba e o submetropolitano era Londrina e Maringá. Mais uma vez ratificava-se que Londrina apresentava uma oferta e distribuição de bens e serviços bastante complexa e uma área de atuação que, estendia-se do extremo leste do norte do estado até as proximidades de Apucarana, a partir da qual, disputava com Maringá a área de influência. Igualmente ao estudo anterior, o nível metropolitano do Paraná estava em Curitiba, mas com as ressalvas já apontadas anteriormente.

No começo dos anos de 1990, Londrina estava em ritmo de continuidade de seu dinamismo - mesmo enfrentando as ações negativas do neoliberalismo - dado agora pela expansão das atividades comerciais através da implantação de mais um shopping center; da expansão da industrialização, tanto aquela com base no capital local e regional, como nas transferências industriais de plantas antes localizadas em regiões metropolitanas, tanto de capital nacional e internacional; expandiam-se os investimentos em serviços especializados em diversos segmentos, fossem para a 
produção propriamente dita, as de consumo como saúde de alta complexidade, educação superior e particularmente mestrado e doutorado, serviços de telecomunicações com implantação de call-center de operadora nacional de telefonia móvel; consultorias jurídicas, ambientais, dentre outros. O estudo do IBGE (2000) ratificou a posição de Londrina na rede urbana com centralidade muito forte que correspondia ao nível submetropolitano.

O trabalho realizado pelo IPEA (2001) configura-se em outra contribuição ao entendimento da rede urbana brasileira que, buscava caracterizar a rede naquele momento bem como identificar tendências. Centrou foco em três vertentes de análise:

\begin{abstract}
A primeira considera os processos econômicos gerais que estão na base da estruturação e do desenvolvimento da rede urbana do Brasil. A segunda leva em conta os processos econômicos regionais e seus desdobramentos na configuração e nas tendências da rede de cidades de cada uma das grandes regiões geográficas do país. A terceira refere-se à manifestação de processos característicos da tipologia da rede urbana - o tamanho, a função e a forma urbana -, enfocando essas manifestações seja para o país como um todo, seja para cada uma das grandes regiões geográficas (IPEA, 2001, p. X, v. 2)
\end{abstract}

Destas análises obtiveram-se as redes urbanas das grandes regiões, a hierarquia da rede urbana, os sistemas urbano-regionais e o quadro de composição das aglomerações urbanas. Realizou discussão sobre as principais transformações espaciais da economia e seus impactos no processo de urbanização e na própria rede urbana; principais tendências do desenvolvimento regional brasileiro e suas implicações para a estruturação do sistema urbano do país, com ênfase nas transformações ocorridas nos anos 1980 e início da década de 1990 (IPEA, 2001, p. $\mathrm{XI}, \mathrm{v}$. 2).

Do ponto de vista da centralidade, o estudo utilizou-se das análises realizadas pelo IBGE (1993) e considerou Londrina como sendo de forte centralidade, isto é, predominantemente submetropolitano. Mas acorde aos objetivos da pesquisa, a considerou uma aglomeração urbana não metropolitana. Baseando-se nos estudos realizados nos anos de 1960 e 1970 quando foram definidos os critérios para criação das regiões metropolitanas (GALVÃO et.al, 1969) e identificação das aglomerações urbanas metropolitanas e não metropolitanas conforme Davidovich e Lima (1975), fez a atualização dos números para os critérios utilizados. 
Para aglomerações urbanas não metropolitanas decorrentes da expansão de um único núcleo urbano, Davidovich e Lima (1975) estabeleciam que este deveria apresentar 100 mil habitantes e no estudo do IPEA foi ampliado para 200 mil habitantes; para as aglomerações decorrentes da expansão de dois ou mais núcleos, o total deveria ser de 75 mil habitantes, e para o IPEA este foi elevado para 150 mil habitantes; para a delimitação das aglomerações, envolvendo os municípios/cidades do entorno, o elemento central nas pesquisas dos anos de 1960/1970 era apresentar uma densidade demográfica de 60 habitantes por $\mathrm{km}^{2}$ e 65\% da População Economicamente Ativa nos setores secundário e terciário. Estas taxas foram mantidas pelo IPEA.

Com base em tais critérios, Londrina apresentava-se como uma aglomeração urbana não metropolitana, enquanto no estudo específico para a Região Sul, foi considerada uma aglomeração de maior porte (IPEA, 2000, p. 65, v. 6). Para o citado órgão,

As aglomerações urbanas não-metropolitanas [sic] distinguem-se: ora por configurar manchas caracteristicamente de ocupação contínua, ora por guardar uma proximidade geográfica, serem densas, populosas, porém com descontinuidade de mancha de ocupação - sendo, contudo, fortemente articuladas na mesma dinâmica econômica -, ora por decorrer de eixos menos populosos ou densos mas também fortemente articulados numa mesma dinâmica econômica com relevância na base produtiva dos estados (IPEA, 2000, p. 58, v. 6).

Inseria-se no sistema urbano-regional de Curitiba, "[...] obtido a partir de agregação de áreas de regiões de influência das cidades, segundo critérios de contiguidade espacial e de dependência funcional" (IPEA, 2001, p. 359, v.2). Mas, o estudo ressaltava que a aglomeração urbana de Londrina apresentava forte importância regional por desempenhar funções "[...] que se equiparam a Curitiba no atendimento a demandas de alta e baixa complexidade" (IPEA, 2000, p. 70-71); por sua participação no valor adicionado estadual naquele momento de $7,10 \%$; pelas atividades comerciais e prestadoras de serviços; além de um setor industrial diversificado.

Necessário citar que Londrina é sede de uma região metropolitana, instituída em 1998 e em 2013 era formada por 25 municípios. Muitos destes foram inclusos nos últimos anos a partir de mecanismos políticos que lhes permitiram acesso aos 
programas federais de investimentos, como o Programa de Aceleração do Crescimento e o Programa Minha Casa Minha Vida. Por disputas políticas, Apucarana não está inclusa na Região Metropolitana de Londrina.

As regiões metropolitanas são regiões de planejamento, cujos critérios para suas institucionalizações são bastante heterogêneos, especialmente a partir de 1988, quando tal processo passou para as unidades da federação. Além destes elementos, o planejamento com vistas à busca de recursos e soluções para diversos problemas, não tem sido efetivamente realizado na grande maioria das mesmas.

Assim, o presente trabalho extrapola esta questão administrativa, concentrando-se na área onde ocorrem os mais importantes fluxos de pessoas, mercadorias, informações, atividades de integração e complementaridade funcional.

Trata-se da aglomeração urbana de Londrina, formada por sete municípios, que apresenta características e atividades similares às metropolitanas. A começar pela própria forma urbana conforme figura 01. Esta permite verificar que desde 1975, Londrina e Cambé já se colocavam em processo de conurbação, que prosseguiu ao longo do período apresentado.

Ibiporã em processo contínuo de expansão de sua área urbana em sentido oeste, estava quase totalmente conurbada com Londrina a partir de 2008 , ampliando a ocupação ao longo da rodovia BR 369; Jataizinho uma pequena cidade localizada a oeste do rio Tibagi, não apresentou crescimento urbano significativo, mas está inclusa na aglomeração urbana mediante os fortes deslocamentos pendulares.

Rolândia por sua vez, também apresentou contínuo crescimento de sua área urbana tanto em direção a Cambé como Arapongas, mas ainda não apresenta-se totalmente conurbada, a não ser nas faixas ao longo da rodovia BR 369. Arapongas e Apucarana também apresentaram conforme a figura 1, contínua expansão da área urbana, mas ainda não se encontram totalmente conurbada. Mas há se que fazer referência que, a distância entre Londrina e Apucarana é de $60 \mathrm{Km}$, chamando-se a atenção que neste percurso tem-se mais três cidades. 


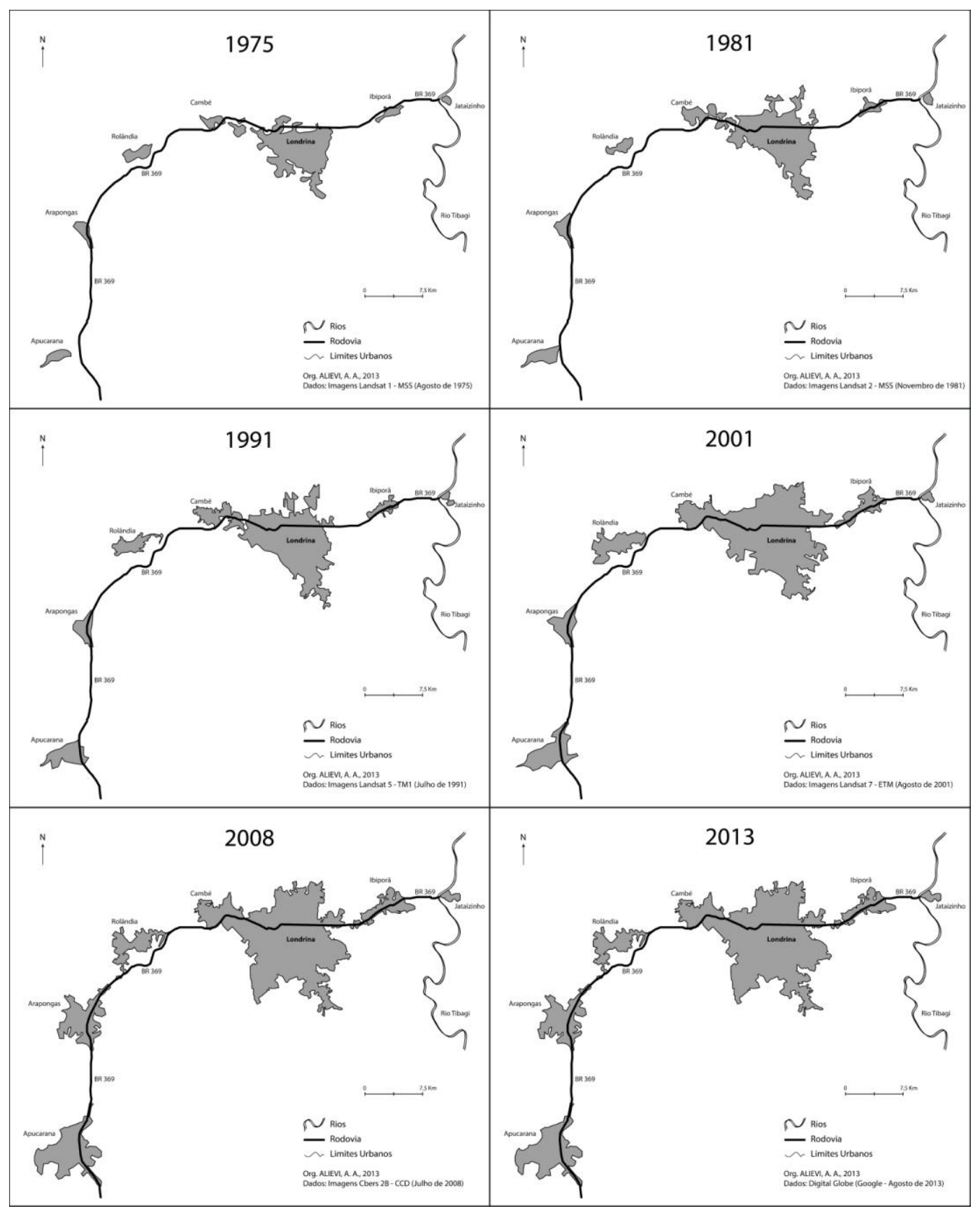

Figura 01: Evolução da Aglomeração Urbana de Londrina - PR: 1975 - 2013

O quadro 1 permite verificar a evolução da população total e urbana das cidades da aglomeração urbana entre 1970-2010, chamando-se atenção para o fato de: no período considerado ocorreu crescimento positivo da população total dos municípios, à exceção de Jataizinho que perdeu população entre 1970-1980; todos os municípios tiveram crescimento positivo de suas populações urbanas; verifica-se que há diferenças nos índices de crescimento da população total e urbana entre as 
cidades e municípios; em 2010 as taxas de urbanização superavam a 94\%, com destaque para Londrina e Arapongas com taxa superior a 97\%; no conjunto somavam 914 mil habitantes urbanos em 2010.

Quadro 1: Evolução da população total e urbana dos municípios da aglomeração urbana de Londrina: 1970-2010

\begin{tabular}{|l|r|r|r|r|r|r|r|r|r|r|}
\hline Munic. & \multicolumn{2}{|c|}{1970} & \multicolumn{2}{c|}{1980} & \multicolumn{2}{c|}{1991} & \multicolumn{2}{c|}{2000} & \multicolumn{2}{c|}{2010} \\
\hline & Total & Urbana & Total & Urbana & Total & Urbana & Total & Urbana & Total & Urbana \\
\hline Londrina & 215.576 & 156.352 & 292.790 & 257.899 & 381.474 & 355.347 & 447.065 & 433.369 & 506.645 & 493.457 \\
\hline Cambé & 35.621 & 13.399 & 53.856 & 44.714 & 73.842 & 66.817 & 88.186 & 81.942 & 96.735 & 92.956 \\
\hline Rolândia & 40.657 & 16.716 & 41.452 & 25.096 & 43.776 & 35.276 & 49.410 & 44.650 & 57.870 & 54.758 \\
\hline Ibiporã & 27.193 & 12.999 & 27.624 & 20.064 & 35.168 & 30.728 & 42.153 & 39.141 & 48.200 & 45.896 \\
\hline Jataizinho & 10.826 & 3.990 & 9.558 & 6.646 & 10.428 & 8.390 & 11.327 & 10.317 & 11.859 & 11.037 \\
\hline Arapongas & 51.210 & 36.609 & 54.688 & 48.213 & 64.556 & 60.025 & 85.428 & 81.790 & 104.161 & 101.862 \\
\hline Apucarana & 69.302 & 41.613 & 80.245 & 63.678 & 95.064 & 86.079 & 107.827 & 100.249 & 120.884 & 114.104 \\
\hline
\end{tabular}

Fonte: IBGE, 1970-2010. Org. Autor, 2014

Neste conjunto estão os maiores deslocamentos pendulares, porque outros são realizados entre Londrina e cidades localizadas tanto ao norte como ao sul da mesma, mas com menor intensidade. O quadro 2 permite verificar que, os destaque são as linhas Cambé - Ibiporã e Cambé - Londrina, as duas cidades cujos processos de conurbação são mais intensos e cujas linhas de transporte metropolitano foram implantadas no final do anos de 1980. Outro aspecto importante é que, as linhas não são unidirecionais, isto é, não são exclusivamente de partida de Londrina, evidenciando uma importante divisão do trabalho, como é o caso da linha Apucarana - Rolândia, com passagem por Arapongas.

Este quadro geral dos deslocamentos pendulares pode ser inicialmente compreendido, mediante compreensão do conjunto das atividades econômicas presentes nas cidades envolvidas, particularmente a geração de empregos, conforme quadro 3. 
Quadro 2: Deslocamentos pendulares entre as cidades da aglomeração urbana de Londrina - PR: maio de 2013 a abril de 2014 (ida e volta).

\begin{tabular}{|l|l|c|l|}
\hline \multicolumn{1}{|c|}{ Linhas } & $\begin{array}{l}\text { Total anual } \\
\text { passageiros }\end{array}$ & $\begin{array}{l}\text { Média diária } \\
\text { passageiros } \\
\text { (20 dias) }\end{array}$ & $\begin{array}{l}\text { Ano } \\
\text { Implantação } \\
\text { da linha }\end{array}$ \\
\hline $\begin{array}{l}\text { Cambé- } \\
\text { lbiporã }\end{array}$ & 3.409 .059 & 15.204 & 1988 \\
\hline $\begin{array}{l}\text { Londrina- } \\
\text { Cambé }\end{array}$ & 3.495 .069 & 14.563 & 1988 \\
\hline $\begin{array}{l}\text { Londrina- } \\
\text { Rolândia }\end{array}$ & 1.030 .410 & 4.293 & 1998 \\
\hline $\begin{array}{l}\text { Londrina- } \\
\text { Jataizinho }\end{array}$ & 742.228 & 3.093 & 1989 \\
\hline $\begin{array}{l}\text { Londrina- } \\
\text { lbiporã }\end{array}$ & 607.571 & 2.532 & 1988 \\
\hline $\begin{array}{l}\text { Apucarana- } \\
\text { Rolândia }\end{array}$ & 1.101 .101 & 4.588 & 1998 \\
\hline
\end{tabular}

Fonte: PARANÁ, 2014. Org.: Autor, 2014.

Quadro 3: Total de estabelecimentos e trabalhadores segundo setores do IBGE nos municípios da aglomeração urbana de Londrina, 2012

\begin{tabular}{|c|c|c|c|c|c|c|c|c|c|c|c|c|}
\hline \multirow[t]{2}{*}{ Município } & \multicolumn{2}{|c|}{$\begin{array}{c}\text { Indústria } \\
\text { Transformação }\end{array}$} & \multicolumn{2}{|c|}{$\begin{array}{c}\text { Construção } \\
\text { Civil }\end{array}$} & \multicolumn{2}{|c|}{$\begin{array}{l}\text { Comércio } \\
\text { Varejista e } \\
\text { Atacadista }\end{array}$} & \multicolumn{2}{|c|}{ Serviços } & \multicolumn{2}{|c|}{ Adm. Pública } & \multicolumn{2}{|c|}{$\begin{array}{l}\text { Agropec., Ext. } \\
\text { Veg., Caça e } \\
\text { Pesca }\end{array}$} \\
\hline & N.est. & N.trab. & N.est. & N.trab. & N.est. & N.trab. & N.est. & N.trab. & N.est. & N.trab. & N.est. & N.trab. \\
\hline Apucarana & 1.039 & 14.442 & 303 & 1.689 & 1.465 & 7.610 & 1.085 & 9.216 & 7 & 1.473 & 235 & 503 \\
\hline Arapongas & 555 & 18.245 & 195 & 548 & 1.368 & 7.733 & 896 & 6.267 & 8 & 3.151 & 190 & 959 \\
\hline Cambé & 434 & 8.709 & 169 & 883 & 933 & 5.923 & 528 & 3.762 & 4 & 2.218 & 185 & 521 \\
\hline Ibiporã & 177 & 3.050 & 73 & 418 & 433 & 2.594 & 285 & 2.383 & 3 & 1.393 & 105 & 285 \\
\hline Jataizinho & 30 & 455 & 9 & 31 & 89 & 243 & 62 & 424 & 2 & 432 & 65 & 104 \\
\hline Londrina & 1.824 & 28.852 & 1.321 & 11.596 & 7.130 & 43.550 & 7.031 & 71.038 & 11 & 8.717 & 697 & 3.335 \\
\hline Rolândia & 270 & 10.187 & 111 & 534 & 709 & 3.984 & 472 & 3.084 & 3 & 1.322 & 215 & 895 \\
\hline
\end{tabular}

Fonte: Brasil, 2012. Org.: Autor, 2014.

Dos 07 municípios, quatro apresentam predomínio do emprego industrial: Apucarana apresenta um setor industrial com especialização em confecções de boné, concentrando mais de $70 \%$ da produção nacional, além de outros segmentos importantes como alimentício e de couro (VIETRO, 20111); Arapongas coloca-se como outra cidade com especialização produtiva, sendo um dos quatro mais importantes polos moveleiros do país (FRESCA, 2004; BRAGUETO, 2007); Rolândia apresenta um setor industrial predominantemente alimentício com destaque para as agroindústrias avícolas; Cambé tem setor industrial bastante diversificado, tendo recebido muitas plantas industriais de capital nacional e 
internacional, transferidas de metrópoles para a cidade nos anos de 1990 e começo do século XXI; Londrina por sua vez, apresenta o maior número absoluto de empregos industriais dentre todas as cidades, cujo setor é diversificado mas com predomínio no confeccionista e alimentício; tem no setor de serviços a maior geração de empregos. $O$ mesmo ocorre com lbiporã que tem maior geração de empregos nos serviços, mas com pequena diferença em relação ao setor industrial. Jataizinho apresenta predomínio de empregos nos serviços, mas aqueles públicos, seguido pelos empregos industriais.

Diante destes elementos, a aglomeração urbana de Londrina - PR coloca-se efetivamente como de maior porte, conforme apontado pelo IPEA, mas cujos índices ultrapassam em muito aqueles levantados no estudo. A favor ainda destas considerações, está o fato de Londrina apresentar um conjunto expressivo de serviços quaternários (GOTTMANN, 1979) como consultorias jurídicas diversas, auditorias, ensino superior, etc.; de um complexo conjunto de atividades comerciais representados inicialmente pela presença de 05 shopping centers e mais um em construção, exercendo forte processo de descentralização intraurbana, entre outros (FRESCA, 2013).

\section{REDE URBANA OU CENTROS DE GESTÃO DO TERRITÓRIO? O REGIC DE 2008 E OS PROBLEMAS DA CENTRALIDADE DE LONDRINA}

Diferente foi o último estudo das Regiões de Influência das Cidades (IBGE, 2008) em que houve mudanças do ponto de vista dos encaminhamentos teóricos. Em primeiro lugar deu-se continuidade ao entendimento do nível de centralidade das cidades a partir da oferta e distribuição de bens e serviços, identificando a partir desta, a área de influência. Mas, a este foram acrescidos outros referenciais que, apoiados em redes técnicas de comunicação e informação, gestão pública e empresarial, ensino superior, dentre outros, buscaram entender tanto a rede de distribuição de bens e serviços como aquela definida por relações horizontais não hierárquicas de complementaridade e cooperação (IBGE, 2008, p. 9).

Em outras palavras, superpuseram dois enfoques analíticos na rede urbana: Christaller com os acréscimos à formulação clássica (CORRÊA, 1982), mais a discussão atual que, inserida na globalização, procurou dar conta do papel das 
redes técnicas controladas por grandes empresas em direção a identificar os centros inseridos em redes globais e aqueles com forte papel na gestão pública e empresarial.

Assim,

\begin{abstract}
Para a definição dos centros da rede urbana brasileira, buscam-se informações de subordinação administrativa no setor público federal, para definir a gestão federal, e de localização das sedes e filiais de empresas, para estabelecer a gestão empresarial. A oferta de distintos equipamentos e serviços capazes de dotar uma cidade de centralidade - informações de ligações aéreas [...] cobertura das emissoras de televisão [...] ensino superior [...] presença de domínios de Internet - complementa a identificação dos centros de gestão do território (IBGE, 2008, p. 09).
\end{abstract}

Este trabalho não apresenta os mesmos elementos utilizados nos estudos precedentes porque, foram acrescidos outros fundamentos analíticos e a busca de outros tipos de centralidades das cidades da rede urbana nacional, como os centros de gestão do território federal e empresarial. Do ponto de vista das centralidades da rede urbana brasileira teve-se: as metrópoles subdivididas em $A, B$ e $C$; capitais regionais subdivididas em $A, B$, e $C$; centros sub-regionais subdivididos em $A$ e $B$; centros de zona subdivididos em A e B e os centros locais.

O resultado apresenta vários problemas e dificuldades analíticas, a começar pela eliminação da centralidade submetropolitana, num momento em que, aprofundam-se os processos que complexificam a rede urbana nacional. Tem-se ainda a continuidade do processo de metropolização no país, seja pela constituição de novas metrópoles, completas ou incompletas para relembrar anteriores elementos analíticos (SANTOS, 1982 a), seja pela formação ou ampliação de aglomerações urbanas de diversos tipos, mediante processos de expansão de áreas urbanas para atendimento de diferentes demandas produtivas, de consumo e habitação da força de trabalho, dentre outros.

Necessário explicitar que as capitais regionais,

[...] também se relacionam com o estrato superior da rede urbana. Com capacidade de gestão no nível imediatamente inferior ao das metrópoles, têm área de influência de âmbito regional, sendo referidas como destino, para um conjunto de atividades, por grande número de municípios. Como o anterior, este nível também tem três subdivisões. O primeiro grupo inclui as capitais estaduais não classificadas no nível metropolitano e Campinas. $\mathrm{O}$ segundo e o terceiro, além da diferenciação de porte, têm padrão de localização regionalizado, com o segundo mais presente no Centro-Sul, e o terceiro nas demais regiões do País (IBGE, 2008, p. 11). 
Londrina foi considerada neste estudo como capital regional $\mathrm{B}$, significando inicialmente que sua centralidade através da distribuição de bens e serviços foi reduzida comparativamente aos estudos anteriores. Questiona-se tal redução vinculada ao fato da cidade apresentar o maior e mais diversificado conjunto de atividades terciárias após Curitiba no âmbito estadual. Neste aspecto, a cidade já apresentava no momento do estudo (2007/2008) além do seu núcleo central, um subcentro espontâneo, 5 shopping centers; de ter superintendências, escritórios regionais, delegacias, etc. dos principais órgãos públicos federais; de apresentar o segundo mais importante conjunto de serviços médico-hospitalares de elevada complexidade do estado; de apresentar um vigoroso setor de educação superior congregando mais de 36 mil alunos de graduação e mais de 7 mil alunos de pósgraduação (FRESCA, 2013).

Outro aspecto importante são as redes técnicas, um dos critérios utilizados pelo IBGE (2008). Benaduce (1999) evidenciava ao papel de Londrina do ponto de vista da concentração de rede de informação, situação esta ratificada por Santos (2014) ao discutir as redes de telecomunicações para o estado do Paraná. Baseando-se na telefonia fixa, móvel e rede de fibras ópticas, demonstrou o uso corporativo do território, colocando Londrina como a segunda mais importante do estado, do ponto de vista da presença das redes técnicas.

Questiona-se ainda centralidade atribuída à cidade em tela, tendo em vista que o próprio IBGE (2008, p. 141), ao especificar os dados sobre gestão empresarial, colocava a existência de 9 sedes sociais de empresas em Londrina, número esse superior a muitas capitais estaduais, que apresentavam nível de centralidade maior que Londrina e nem constavam nos dados sobre esta gestão. Evidente que do ponto de vista da gestão pública, esta é superior nas capitais estaduais comparativas à Londrina, conforme os próprios elementos considerados para definição da centralidade.

Este questionamento pode ser estendido para outras variáveis e critérios utilizados pelo IBGE (2008), mas evidencia-se que no estabelecimento da centralidade, deu-se peso acentuado para a gestão pública em detrimento da oferta de bens e serviços pela cidade. Isto implica que o estudo em tela pouco contribui para dar indicativos claros da inserção de Londrina na rede urbana mediante oferta de bens e serviços. Isto não significa que os demais elementos presentes no estudo 
como a gestão empresarial e pública não deva ser estudada e pesquisada, mas o problema foi a maneira através da qual, agregou-se estes para estabelecer o nível de centralidade das cidades da rede urbana nacional.

Quando efetuou-se tal procedimento, acabou-se por dar peso significativo à gestão pública em detrimento das atividades econômicas do terciário e para vários casos, até mesmo da gestão econômica e territorial mediante presença de sede de empresas. Os elementos apontados devem servir de ponto de partida para novos estudos, no sentido de evidenciar que a análise de diferentes redes (a de distribuição de bens e serviços, de comunicação, de gestão, dentre outras), com fundamentos teóricos e critérios distintos, deve ser realizada. Mas que não se transforme em caminho impeditivo de aprofundar a compreensão dos diferentes caminhos qualitativos e quantitativos da inserção de uma cidade na rede urbana nacional através das diferentes atividades.

\section{CONSIDERAÇÕES FINAIS}

Os estudos realizados sobre a rede urbana brasileira, permitiram verificar que Londrina teve sucessivamente ampliado seu nível de centralidade até o começo do século XXI. De capital regional nos anos de 1950 permaneceu até o final dos anos de 1960, galgando avanços no final dos anos de 1970 quando assumiu centralidade no nível submetropolitano, que se manteve até 1993. No final desta década, o estudo do IPEA ratificou sua centralidade, mas avançou no sentido de incluir o quadro de composição das aglomerações urbanas. Desta forma evidenciava-se que a cidade em tela, além de seu escalão submetropolitano, era efetivamente reconhecida como uma aglomeração urbana de maior porte, embora não metropolitana. Em outras palavras, uma grande cidade, complexa do ponto de vista de suas atividades econômicas, mas não alcançando elementos que a qualificassem como metrópole.

Diante deste conjunto torna-se claro que os princípios adotados pelo Regic de 2008, rebaixando Londrina para capital regional B, são bastante questionáveis já que, priorizaram elementos da gestão pública para estabelecer a centralidade.

Os problemas deste estudo foram tantos, que em 2014 o IBGE publicou trabalho específico sobre Redes e fluxos do território: gestão do território 2014, 
procurando "[...] compreender como as diferentes regiões e cidades se conectam através da gestão do território e quais são os centros que concentram a capacidade de comando e controle do País" (IBGE, 2014, p. 10). Esta pesquisa evidenciou que, do ponto de vista da gestão pública federal, Londrina ocupa posição marginal já que não é capital estadual.

Por outro lado, a gestão empresarial mediante presença de sedes e filiais de empresas, demonstrou que Londrina ocupava na intensidade das ligações dentre os 43 maiores municípios para o ano de 2011 , a $18^{a}$ posição com 507 empresas sedes e 1771 empresas controladas a partir da mesma, ou seja, filiais (IBGE, 2014, p. 75).

Fica evidente que Londrina apresenta uma complexidade bastante expressiva do ponto de vista de seu processo de metropolização, seja pela forma, pelos deslocamentos pendulares, pelas atividades econômicas, de sua capacidade de gestão pública em termos regionais, gestão privada, dentre outros, inserindo-a na rede urbana como centro submetropolitano.

\section{REFERÊNCIAS}

BENADUCE, Gilda M. C. Rede de informação e novas espacialidades no Paraná. 1999. Tese (Doutorado em Geografia) - Unesp, Presidente Prudente.

BESSA, K. C. F de O. Convergências e divergências da urbanização em áreas de cerrado: a dinâmica urbano-regional de Uberaba e Uberlândia (MG). 2007. Tese (Doutorado em Geografia) - UFRJ, Rio de Janeiro.

BRAGUETO, Cláudio R. O aglomerado urbano-industrial de Londrina: sua constituição e dinâmica industrial. 2007. Tese (Doutorado em Geografia) - USP, São Paulo.

BRASIL. Ministério do Trabalho e Emprego. Base estatística RAIS: Relação anual de informações sociais, 2012. Brasília, 2012.

CAMPOS, Margarida Cássia. A Embrapa/soja em Londrina-PR: a pesquisa agrícola de um país moderno. 2010. Tese (Doutorado em Geografia) - UFSC, Florianópolis.

CASARIL, C. C. Formação sócio-espacial de Londrina-PR e seu processo precoce de verticalização urbana. Revista Discente Expressões Geográficas,

Florianópolis, v. 7, p. 32-53, 2011. 
CORRÊA, R. L. Repensando a teoria dos lugares centrais. In: SANTOS, M. (org.). Novos rumos da geografia brasileira. São Paulo: Edusp, 1982.

DAVIDOVICH, F. e LIMA, O.M. Buarque de. Contribuição ao estudo de aglomerações urbanas no Brasil. Revista Brasileira de Geografia, Rio de Janeiro, v. 37, n. 1, jan/mar, 1975.

FRESCA, T. M. A estruturação da rede urbana do norte do Paraná. In: FRESCA, T. M.; CARVALHO, M. S. (org.). Geografia e norte do Paraná: um resgate histórico. Londrina: Edições Humanidades, 2007. v. 2.

FRESCA, T. M. Industrialização no norte do Paraná na década de 1990: transferência industrial e estratégias de crescimento. Ciência Geográfica, Bauru, v. 10, n. 3, 2004.

FRESCA, T. M. Produção do espaço metropolitano de Londrina - PR: novas centralidades e mercado imobiliário. Revista de Geografia, Recife, v. 30, n. 2, p. 3250, 2013 a.

FRESCA, T. M. Londrina - PR como espaço metropolitano: uma análise a partir dos serviços superiores. ENCUENTRO DE GEÓGRAFOS DE AMERICA LATINA, 2013, Lima - Peru. Anais... Reencuentro de saberes territoriales latinoamericanos, 2013. v. 1. p. 1-19.

GALVÃO et. al. Áreas de pesquisa para determinação de áreas metropolitanas. Revista Brasileira de Geografia, Rio de Janeiro, v. 31, n.4, p.53-127, 1969.

GEIGER, P. P. Evolução da rede urbana brasileira. Rio de Janeiro: CBPE/INEP/Ministério da Educação e Cultura, 1963.

GOTTMANN, Jean. A dinâmica das grandes cidades. Boletim Geográfico, Rio de Janeiro, v. 34, n. 255, out./dez., 1976. p. 5-14.

IBGE. Redes e fluxos do território: gestão do território. Rio de Janeiro: IBGE, 2014. Disponível em: <

http://www.ibge.gov.br/home/geociencias/geografia/redes fluxos/gestao do territori o 2014/default.shtm?c=8>. Acesso em junho 2014.

IBGE. Censo demográfico: 2010. Disponível em: < http://www.ibge.gov.br/home/estatistica/populacao/censo2010/default.shtm >. Acesso em junho 2014.

IBGE. Divisão do Brasil em regiões funcionais urbanas. Rio de Janeiro: IBGE, 1972.

IBGE. Regiões de influência das cidades. Rio de Janeiro: IBGE, 1987.

IBGE. Regiões de influência das cidades: 1993. Rio de Janeiro: IBGE, 2000. 
IBGE. Regiões de influência das cidades: 2007. Rio de Janeiro: IBGE, 2008.

IPEA. Caracterização e tendências da rede urbana do Brasil: estudos básicos para a caracterização da rede urbana. Brasília: IPEA, IBGE, Unicamp, 2001. v. 2.

IPEA. Caracterização e tendências da rede urbana do Brasil: rede urbanas regionais: Sul. v.6. Brasília: IPEA, IBGE, Unicamp/IE/NESUR/Ipardes, 2000. v. 6.

LINARDI, M. C. N. Pioneirismo e modernidade: a urbanização de Londrina - PR. Tese (Doutorado em Geografia) - USP, São Paulo, 1995.

MELO, Vanessa J. O conjunto Centro Comercial de Londrina - PR: o edifício multifuncional, a arquitetura e a modernização da cidade. 2014. Dissertação (Mestrado em Arquitetura) - UEM, Maringá.

PARANÁ. DEPARTAMENTO DE ESTRADAS DE RODAGEM. Movimento de passageiros por linha: maio de 2013 a abril de 2014. Curitiba, 2014.

PRANDINI, N. Aspectos da geografia urbana de Londrina. In: FRESCA, T. M.; CARVALHO, M. S. (org.). Geografia e norte do Paraná: um resgate histórico. Londrina: Edições Humanidades, 2007. v. 2.

SANTOS, M. Sociedade e espaço: a formação social como teoria e método. In: . Espaço e sociedade: ensaios. Petrópolis: Vozes, 1982.

SANTOS, M. Ensaios sobre a urbanização latino-americana. São Paulo: Hucitec, 1982 a.

SANTOS, Letícia K. As redes de telecomunicações no estado do Paraná e o uso corporativo do território: fluidez e regulação. 2014. Dissertação (Mestrado em Geografia) - Unicentro, Guarapuava.

VIETRO, Anderson de F. A indústria confeccionista no Norte do Paraná. 2011. Dissertação (Mestrado em Geografia) - UFSC, Florianópolis.

(Recebido em 28.08.2014; Aceito em: 09.02.2015) 